\title{
Laboreal
}

Volume $1 \mathbf{N}^{\circ} 1$ | 2005

Varia

\section{Uso dos recursos, adaptação dos saberes e gestão da autonomia na decisão terapêutica}

Uso de los recursos, adaptación de los conocimientos y gestión de la autonomia en la decisión terapéutica

Usage des ressources, adaptation des savoirs et gestion de l'autonomie dans la décision thérapeutique

Resources use, knowledge adaptation and autonomy management in therapeutic decision

\section{Vanina Mollo}

\section{(2) OpenEdition}

\section{Journals}

Edição electrónica

URL: http://journals.openedition.org/laboreal/14072

DOI: $10.4000 /$ laboreal. 14072

ISSN: 1646-5237

\section{Editora}

Universidade do Porto

\section{Refêrencia eletrónica}

Vanina Mollo, « Uso dos recursos, adaptação dos saberes e gestão da autonomia na decisão terapêutica », Laboreal [Online], Volume 1 NN$^{0} 1$ | 2005, posto online no dia 01 dezembro 2005, consultado o 24 setembro 2020. URL : http://journals.openedition.org/laboreal/14072 ; DOI : https:// doi.org/10.4000/laboreal.14072

Este documento foi criado de forma automática no dia 24 setembro 2020.

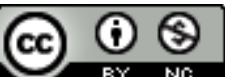

Laboreal está licenciado com uma Licença Creative Commons - Atribuição-NãoComercial 4.0 Internacional. 


\section{Uso dos recursos, adaptação dos saberes e gestão da autonomia na decisão terapêutica}

Uso de los recursos, adaptación de los conocimientos y gestión de la autonomia en la decisión terapéutica

Usage des ressources, adaptation des savoirs et gestion de l'autonomie dans la décision thérapeutique

Resources use, knowledge adaptation and autonomy management in therapeutic decision

Vanina Mollo

\section{REFERÊNCIA}

Mollo, V. (2005). Usage des ressources, adaptation des savoirs et gestion de l'autonomie dans la décision thérapeutique. Thèse de Doctorat en Ergonomie, Laboratoire d'ergonomie du CNAM, Paris.

\section{NOTA DO EDITOR}

Manuscrito recebido em : Agosto/2005

Aceite após peritagem em : Outubro/2005

Em numerosas situações de trabalho, os operadores são submetidos a regras mais ou menos constrangedoras às quais se devem referir para tomar decisões, e que têm geralmente por objectivo assegurar a qualidade e a fiabilidade da produção, quer esta se reporte a um produto ou a um serviço. Esta vontade de prescrever a actividade dos 
operadores suscita duas questões, uma relativa ao estatuto dos desvios às regras, a outra à autonomia dos operadores.

2 Podem ser distinguidos dois modelos de utilização das regras (Dekker, 2003). 0 primeiro considera as regras como o meio mais seguro de assegurar a qualidade e a fiabilidade da produção. $O$ comportamento esperado dos operadores é então o de se conformarem às regras. No caso contrário, as acções de melhoria consistirão em se assegurar que os operadores conhecem bem as regras e que as seguem. $O$ segundo modelo, por outro lado, considera as regras como recursos incompletos, o que quer dizer que desde a sua concepção, elas não consideram todas as situações encontradas na prática quotidiana. $O$ comportamento esperado dos operadores consiste não em se conformar estritamente às regras existentes, mas em determinar quando e como se adaptar. Se eles falham aplicando uma regra que não está adaptada à situação ou tentando uma adaptação que falha, as acções de melhoria visarão controlar e compreender os diferentes tipos de desvios, a fim de definir as situações críticas e assistir os operadores no seu julgamento de adaptabilidade, para melhorar a sua capacidade de julgar quando e como adaptar.

3 Segundo o modelo considerado, o espaço atribuído à autonomia dos operadores difere. No primeiro modelo, a autonomia constitui uma fonte de infiabilidade podendo pôr em perigo o bom andamento do sistema, enquanto que no segundo, ela é um recurso indispensável à decisão.

4 É nesta segunda perspectiva que se inscreve este trabalho. A autonomia define-se então como "a capacidade em discernir, em função das situações ou dos contextos, o carácter obrigatório, facultativo, inútil, até por vezes prejudicial das regras, e em fazer variar a submissão em função das contingências" (Everaere, 1999).

5 Estas questões relativas ao estatuto dos desvios às regras e ao espaço atribuído à autonomia dos operadores foram tratadas no contexto da normalização das práticas médicas, e mais particularmente em oncologia, onde se passou progressivamente de uma medicina fundada sobre a peritagem clínica específica dos especialistas à medicina fundada sobre as evidências (Evidence-based Medicine: EBM), definida como "a utilização consciente, explícita e judiciosa da melhor prova disponível relativamente ao cuidado dos pacientes" (Sackett, Rosenberg, Gray, Haynes \& Richardson, 1996). Os médicos dispõem de referenciais terapêuticos sobre os quais se devem apoiar para tomar as decisões de tratamentos. Estes referenciais compilam, sob a forma de regras, os resultados publicados com base em ensaios terapêuticos (Evidence-based working group, 1992) ; assim, tomar uma decisão implica categorizar os casos a partir das regras existentes e aplicar a acção correspondente.

6 O objectivo de uma tal normalização é de melhorar a qualidade dos cuidados administrados aos pacientes e de homogeneizar as práticas. Mas apesar de a sua utilidade manifesta, o EBM não considera a variabilidade dos pacientes, tanto sobre o plano médico (contra-indicações medicamentosas) como no plano das necessidades e preferências, os pacientes podem emitir pedidos particulares que limitam a aplicabilidade dos tratamentos (por exemplo : a recusa de um tratamento) (Knottnerus \& Dinant, 1997 ; Howitt \& Armstrong, 1999 ; Bensing, 2000 ; Freeman \& Sweeney, 2001 ; Haynes, 2002). Este carácter incompleto das regras conduziu ao desenvolvimento de Comités de Concertação Pluridisciplinares (CCP). Trata-se de reuniões de especialistas cujo objectivo é fornecer um parecer sobre casos que comportam elementos perturbadores, isto é factores que impedem a aplicação stricto sensu do referencial. 
$7 \quad 0$ presente estudo, realizado num centro oncológico, aborda estas situações de desvio às regras, e visa compreender o processo de adaptação. Trata-se de colocar em evidência os recursos utilizados pelos médicos para tratar os casos fora do referencial (experiência passada, CCP, colegas), e de analisar o processo de construção da autonomia, isto é, de colocar à frente o estatuto das regras na decisão e de analisar o impacto do colectivo sobre as escolhas individuais. De facto, se este último faz parte integrante da actividade dos médicos (testemunhando a existência dos $\mathrm{CCP}$ ), ele não permite fazer sobressair os efeitos da actividade colectiva sobre o indivíduo. É por esta razão que uma parte importante deste trabalho consistiu em simular a actividade do CCP, pela confrontação dos médicos com as decisões dos seus pares, para analisar os seus efeitos sobre a aprendizagem individual.

8 Para responder a estes objectivos, foi operacionalizada uma metodologia de extracção dos conhecimentos de adaptação. Ela desenrolou-se em duas fases. Na primeira, 19 médicos (6 radioterapeutas, 6 cirurgiões, 6 oncologistas e 1 ginecologista), vistos individualmente, resolveram em voz alta 14 problemas realistas implicando um ou vários elementos perturbadores. Estes últimos correspondem a três tipos de incertezas :

1. - A incerteza sobre a caracterização do problema : a dificuldade assenta na inclusão do problema numa categoria do referencial. Pode tratar-se de valores que não são tidos em conta pelo referencial (por exemplo, não existe referencial relativo ao cancro do seio do homem), de valores situados no limite dos valores de uma classe (idade, tamanho do tumor), ou de dados definitivamente em falta (localização desconhecida do tumor no seio).

2. - A incerteza sobre as características médicas do paciente, que compreende essencialmente os antecedentes médicos (embolia pulmonar) e as patologias associadas do paciente (hipertensão), mas também certas características físicas que contraindicam certos tratamentos (gravidez).

3. - A incerteza relativa à escolha do paciente : trata-se de pedidos específicos formulados pelo paciente (recusa de um tratamento, desejo de engravidar).

9 Os médicos têm uma experiência mínima de 10 anos, e pertencem à mesma rede de cuidados regional. Resolver os problemas significava analisar as características específicas do problema colocado, considerar as soluções terapêuticas potenciais e hierarquizá-las. Estes problemas foram construídos em colaboração com um especialista do centro e diziam respeito não ao diagnóstico, mas à escolha de uma terapêutica.

10 A segunda fase consistiu em efectuar as allo-confrontações individuais : 13 dos 19 médicos foram confrontados individualmente com as soluções dos seus pares a fim de que eles as comentassem (Mollo \& Falzon, 2003; 2004). Estas soluções foram completadas pelos extractos de verbalizações, para que os médicos tivessem acesso às justificações das escolhas dos seus colegas. Este processo de avaliação contrastante permite, por um lado, uma maior explicitação dos conhecimentos recolhidos aquando da primeira etapa, e por outro lado, aceder aos efeitos subjacentes do processo de confrontação posto em prática aquando do CCP, simultaneamente sobre o desenvolvimento dos conhecimentos individuais e colectivos. Nesta segunda fase, que exige mais tempo do que a primeira, e não podendo o tempo concedido por médico exceder $1 \mathrm{~h}$, foram retidos 6 problemas com base na diversidade observada ao nível das soluções propostas (número de soluções diferentes propostas por problema e repartição dos efectivos associados a cada solução) e no grau de divergência entre as diferentes soluções (para certos problemas, as soluções propostas variavam da 
prescrição de um tratamento à supressão desse tratamento). Os extractos de verbalizações foram seleccionados com base na variabilidade dos critérios de decisão utilizados pelos médicos.

11 No final de cada problema tratado, os médicos deviam validar ou modificar as soluções que eles haviam retido aquando da primeira fase a fim de analisar as mudanças eventuais de soluções.

A análise de dados verbais assim recolhidos fez realçar dois resultados principais.

o primeiro atesta que os instrumentos que visam normalizar as práticas médicas e a autonomia dos médicos constituem menos constrangimentos do que os recursos que os médicos utilizam à sua maneira, em função das suas necessidades (Castel \& Merle, 2002). O referencial terapêutico formaliza, sob a forma de regras, os conhecimentos provenientes da literatura científica, facilitando assim o processo de pesquisa de solução. Mesmo numa situação não habitual, ele serve igualmente de base ao raciocínio dos médicos. Esta afirmação assenta sobre duas constatações. Por um lado, os elementos perturbadores foram identificados por todos os médicos, o que mostra que estes reconhecem o desvio à regra, e portanto que esta última constitui a sua referência. Por outro lado, uma vez reparado o desvio, os médicos reflectem sobre a base do referencial que seria aplicado na ausência dos elementos perturbadores. Assim, quando uma situação dada coloca em causa a aplicabilidade do referencial, este não é abandonado mas adaptado. É por isso que falamos de uma adaptação reflectida (Sauvagnac, 2000). No entanto, o universo do referencial estando exclusivamente centrado sobre a patologia, torna-se insuficiente. Os médicos devem necessariamente integrar critérios provenientes de outros universos, nomeadamente o universo dos pacientes (estado clínico e psicológico, crenças...), o universo técnico-organizacional (recursos materiais, organizacionais e temporais), o universo colectivo (colegas, CCP) e o universo do próprio médico, que compreende ao mesmo tempo os conhecimentos advindos da pesquisa clínica e a prática efectiva. Relativamente ao CCP, este oferece aos médicos um meio de reduzir a incerteza à qual eles podem ser confrontados. Dito isto, ele não é exclusivo : os médicos podem admitir um parecer junto dos seus colegas mais do que no $\mathrm{CCP}$, e este último pode ser utilizado para outros fins que o da ajuda à decisão (apoio médico-legal, aprendizagem colectiva, etc.).

14 Assim, apesar dos instrumentos que lhes são impostos, os médicos dispõem de uma autonomia consequente que lhes permite gerir o "potencial de surpresa" característico de todo o domínio de actividade (Woods \& Shattuck, 2000), e, ao fazê-lo, completar as regras existentes especificando os seus valores ou criando novas regras adaptadas aos casos particulares.

O segundo resultado concerne ao impacto do colectivo (CCP) sobre a construção e desenvolvimento da autonomia. Esta assume um papel importante na determinação de soluções inaceitáveis por um lado, certas soluções foram julgadas inadequadas pela maioria dos médicos que as comentaram e, por outro lado, na determinação das soluções aceitáveis : ao contrário do ponto precedente, outras soluções são julgadas aplicáveis pela maioria dos médicos que as avaliaram, apesar de não fazerem parte das suas escolhas iniciais. Enfim, a confrontação com as decisões do outro representa um papel importante na mudança de soluções já que em $48 \%$ dos casos, os médicos modificaram a sua escolha inicial. habituais, e ao fazê-lo, participa no desenvolvimento do espaço de autonomia dos 
médicos. O seu objectivo consiste mais em definir o espaço de soluções possíveis e impossíveis que se aproximam de uma solução única aceitável (ainda que isto possa talvez ser necessário). Assim, ele fornece um quadro de referência aos médicos que lhes permite efectuar as escolhas segundo as suas próprias regras de especialista, assegurando a fiabilidade das decisões tomadas (Mollo, 2004). O CCP é igualmente um instrumento de difusão das regras locais e participa na aprendizagem dos médicos, os quais foram levados a integrar as regras construídas, no decurso da confrontação.

o conjunto destes elementos conduz o ergónomo a interrogarse sobre os meios de favorecer o papel do especialista clínico específico dos médicos na evolução das regras e, mais particularmente, sobre os instrumentos susceptíveis de apoiar a construção e o desenvolvimento de conhecimentos. De facto até aqui, os efeitos induzidos sobre as pessoas e sobre o próprio colectivo tornaram-se implícitos, estando o CCP mais centrado sobre a produção de decisões adaptadas aos casos particulares do que sobre a construção e desenvolvimento dos conhecimentos. A allo-confrontação individual poderia constituir um instrumento de suporte a esta actividade reflexiva. $O$ interesse deste método é que ele desencadeia uma mudança de representação que resulta do facto do operador se encontrar colocado afastado da sua própria actividade; a confrontação com os saberes do outro condu-lo assim a melhor justificar as suas próprias regras de decisões. No entanto, este método integrado na perspectiva de evolução dos conhecimentos apresenta dois limites essenciais. Por um lado, a evolução do referencial não pode ser encarada senão a partir de uma reflexão colectiva (e não individual) sobre os diferentes problemas encontrados na prática. Por outro lado, ainda que a adaptação local de uma regra possa ser considerada como a premissa de uma nova regra, é a repetição de formas de adaptação similares que permite evoluir para o desenvolvimento de novas regras. É portanto necessário dispor de um número suficiente de casos similares. Uma das vias possíveis é a análise dos casos tratados no CCP, que permitiria a comparação destes casos em função do tipo de soluções propostas para um mesmo problema. Uma solução é então juntar as allo-confrontações individuais e o CCP : os médicos tratariam primeiramente sozinhos um problema, depois exporiam o seu raciocínio aos seus colegas, devendo discutir a lógica de raciocínio e os diferentes tratamentos propostos. A allo-confrontação adquire assim o estatuto de metodologia para a actividade reflexiva colectiva.

É preciso, finalmente, lembrar que para além dos recursos internos à organização, a decisão terapêutica é um processo de cooperação entre o médico e o paciente cuja gestão é deixada à inteira autonomia do médico. A análise dos dados mostra que os conhecimentos de que os médicos dispõem sobre os pacientes encontrados ao longo da sua prática estão na origem de certas soluções de adaptação, sem que estes tenham mesmo formulado um pedido particular. Ela mostra igualmente que o estilo adoptado pelos médicos na relação depende fortemente do grau de acessibilidade dos pedidos. Estes resultados fornecem bases de reflexão relativas à participação dos pacientes no processo de decisão, que constitui uma problemática cada vez mais desenvolvida no domínio da saúde. Eles conduzem, nomeadamente, a pensar que os pedidos dos pacientes, em certas situações (e sob certas condições), poderiam ser introduzidos nos referenciais terapêuticos, a fim de serem considerados na decisão (Flatley, Brennan \& Strombom, 1998 ; Protheroe, Fahey, Montgomery \& Peters, 2000). 


\section{BIBLIOGRAFIA}

Bensing, J.P.D. (2000). Bridging the gap. The separate worlds of evidence-based medicine and patient-centered medicine. Patient Education and Counseling, 39, (1), 17-25.

Castel, P., \& Merle, I., (2002). Quand les normes de pratiques deviennent une ressource pour les médecins. Sociologie du Travail, 44, (3), 337-355.

Dekker, S. (2003). Failure to adapt or adaptations that fail : contrasting models on procedures and safety. Applied Ergonomics, 34, (3), 233-238.

Everaere, C. (1999). Autonomie et collectifs de travail. Lyon : ANACT. Evidence-based medicine working group (1992). Evidence-based medicine. A new approach to teaching practice for medicine. JAMA, 268, (17),2420-2425.

Flatley Brennan, P., \& Strombom, I. (1998). Improving health care by understanding patient preferences. The role of computer technology. Journal of the American Medical Informatics Association, 5, (3), 257-262.

Freeman, A.C., \& Sweeney, K. (2001). Why general practitioners do not implement evidence : qualitative study. British Medical Journal, 323 (7303), 1-5.

Haynes, R.B. (2002). What kind of evidence is it that evidence-based medicine advocates want health care providers and consumers to pay attention to ? BMC Health Services Research, 2, (3), $7 \mathrm{p}$.

Howitt, A., \& Armstrong, D. (1999). Implementing evidence-based medicine in general practice : audit and qualitative study of antithrombotic treatment for atrial fibrillation. British Medical Journal, 318, (7194), 1324-1327.

Knottnerus, A., \& Dinant, G.J. (1997). Medicine based evidence, a prerequisite for evidence based medicine. British Medical Journal, 315 (7116), 1109-1110.

Mollo, V., \& Falzon, P. (2003). Formalizing confrontation methods : a categorization attempt. Proceedings of the XVth Thriennial Congress of International Ergonomics Association, "Ergonomics in the Digital Age", August 24-29, 2003 Seoul, Korea, 4 p.

Mollo, V. (2004). Normalisation et adaptation des règles en cancérologie. In P. Rey, E. Ollagnier, V. Gonik \& D. Ramaciotti (Eds.) Communication au XXXIXème Congrès de la SELF, "Ergonomie et normalisation" : 15-17 septembre 2004, Genève (pp. 221-229). Toulouse : Octarès.

Mollo, V., \& Falzon, P. (2004). Autoand allo-confrontation as tools for reflective activities. Applied Ergonomics, 35, (6), 531-540.

Protheroe, J., Fahey, T., Montgomery, A.A., \& Peters, T.J. (2000). The impact of patients' preferences on the treatment of atrial fibrillation : observational study of patient based decision analysis. British Medical Journal, 320, 1380-1384.

Sackett, D.L., Rosenberg, W.M.C., Gray, J.A.M., Haynes, R.B., \& Richardson, W.S. (1996). Evidencebased medicine, what it is, and what it isn't. British Medical Journal, 312, (7023), 71-72.

Sauvagnac, C. (2000). La construction de connaissances par l'utilisation et la conception de procédures. Contribution au cadre théorique des activités métafonctionnelles. Thèse de doctorat en Ergonomie, CNAM, Paris. 
Woods, D.D. \& Shattuck, L.G. (2000). Distant supervision local action given the potential for surprise. Cognition, Technology and Work, 2, (4), 242-245.

\section{AUTOR}

VANINA MOLLO

Laboratoire d'Ergonomie du CNAM, 41 rue Gay Lussac, 75005 Paris, France vanina.mollo@cnam.fr 